Article

\title{
Effect of Hygrothermal Ageing on Tribological Behaviour of PTFE-Based Composites
}

\author{
Mohammad-Reza Homayoun *, Arash Golchin and Nazanin Emami * \\ Polymer Composites and Biotribology Group, Division of Machine Elements, Department of Engineering \\ Sciences and Mathematics, Luleå University of Technology, 97187 Luleå, Sweden; arash_golchin@yahoo.com \\ * Correspondence: m.r.homayoun@tue.nl (M.-R.H.); Nazanin.Emami@ltu.se (N.E.); \\ Tel.: +31-613-616-829 (M.-R.H.); +46-730-531-939 (N.E.)
}

Received: 23 September 2018; Accepted: 21 November 2018; Published: 26 November 2018

\begin{abstract}
The present study investigates the influence of hygrothermal ageing on the tribological behaviour of polytetrafluoroethylene (PTFE) polymer composites. Three PTFE composites along with unfilled PTFE were tested in sliding contact against Inconel 625 (a Ni-based alloy) plates in both dry and water-lubricated conditions, utilising a unidirectional pin-on-disc tribometer. The tribo-tests were performed at a constant sliding speed of $0.13 \mathrm{~m} / \mathrm{s}$ with a normal load of $84 \mathrm{~N}$ providing an apparent contact pressure of $5 \mathrm{MPa}$. Hygrothermal conditioning was carried out at two different temperatures, and the water absorption evolution and kinetic parameters were estimated. Various characterisation methods were used to identify the wear mechanisms and influence of hygrothermal ageing on the degradation of the filler/matrix. The different tribological behaviour for different PTFE composites was observed within the ageing timeframe. The wear resistance of the fibre-filled samples was reduced compared to the non-aged ones over the ageing timeframe. However, the friction and wear resistance of the bronze-filled PTFE were enhanced by hygrothermal ageing.
\end{abstract}

Keywords: hygrothermal ageing; PTFE; friction; wear

\section{Introduction}

Conventionally used mineral and synthetic oils in hydropower plants pose concerns because of fear of spillage and downstream contamination. Therefore, due to increased environmental concerns, the hydropower industry has strived actively for alternative lubricants to replace oil-based lubricants within their facilities. Thus, oil-free plants are now being introduced by replacing conventional lubricants with water. However, this solution presents challenges regarding material selection. One of the possible material groups is polymers and their composites, because they have advantageous qualities that cannot be achieved with ceramics or hard coatings. The use of polymers and their composites in tribological applications arises from their favourable bulk and surface characteristics [1,2]. Polytetrafluoroethylene (PTFE) and its composites are particularly appealing in load-bearing tribological applications due to their corrosion resistance, low dynamic friction in sliding against metal surfaces under certain conditions, and low water absorption [3].

The tribological and mechanical behaviour of polymer composites are highly temperature-dependent, and the presence of water affects their degradation. Polymer journal bearings in hydropower plants are subjected to harsh environmental conditions such as moisture, elevated temperatures, or a combination of both, which may lead to dilatational expansion, plasticisation, and eventually the degradation of reinforced polymer composites [4].

Polymers and their composites may undergo various reversible and non-reversible changes depending on environmental conditions such as humidity, temperature, and exposure time. 
The water-induced expansion and stresses that are linked to such phenomena can cause reduced damage tolerance and affect the structural durability of the bearing $[5,6]$.

The available evidence seems to suggest that water content increases the molecular chain mobility because of the moisture effect. Hence, the moisture absorbed behaves as a plasticiser, which decreases the relaxation time [7]. Furthermore, the glass transition temperature $\left(T_{\mathrm{g}}\right)$ would be lowered because of induced plastic deformation. Elevated temperatures facilitate the diffusion of water molecules throughout the polymer [6]. Plasticisation and swelling are two possible adverse outcomes of water absorption. Swelling is associated with a differential strain caused by an expansion force applied by the liquid while extending polymeric chains; whereas plasticisation prompts plastic deformation along with decreasing the glass transition temperature $\left(T_{\mathrm{g}}\right)[8]$. These two harmful mechanisms are assumed to create capillarity in polymeric composites.

The combination of residual stresses and hygrothermal forces can be sufficient to cause polymer composite failure, and hence must not be neglected in life estimation and design analysis. Most researchers have suggested that water absorption behaviour follows the one-dimensional Fick's law. The law states that the concentration of the diffusant in the volume element is a function of time $[9,10]$. However, some materials in particular conditions behave in a non-Fickian manner [11,12]. Therefore, understanding the absorption behaviour of the polymer and polymer composites is important in determining the estimated life of the bearing in environments where water is present.

In natural ageing, it may take several years for a polymer composite to degrade. Accelerated ageing is typically used in laboratory conditions to simulate natural ageing. Therefore, the temperature of the environmental ageing condition is increased/decreased beyond the typical service/working condition in order to accelerate the degradation process [5]. Moreover, evaluation of the polymers' tribological response is mostly investigated using non-aged samples without any previous exposure to the lubricant. However, in real applications, the polymers are exposed to different environmental conditions that may alter the mechanical and tribological properties of the polymeric components $[1,3]$.

Other researchers have provided ample support for the assertion that water absorption has an enormous influence on many mechanical properties, including elongation at break, modulus and yield stress, fracture toughness, and hardness [13]. However, there has been limited research on the tribological behaviour of polymer composites under hygrothermal ageing. Hygrothermal ageing experiments on short glass fiber reinforced polyamide 66 (PA66), treated oil palm fibre reinforced polyester (T-OPRP), and ultra high molecular weight polyethylene (UHMWPE) resulted in an increased dynamic friction in the first two cases, while causing an insignificant change in that of the third. Furthermore, the results of wear resistance measurements indicated dependency on the reinforcement rate in the first case, and a notable reduction and inconsiderable variation in the last two cases, respectively [14-16]. To the best of the authors' knowledge, there is no published research on the tribological evaluation of PTFE and its composites considering the effects of hygrothermal ageing. Therefore, further studies are required to investigate the influence of hygrothermal ageing on the tribological behaviour of these polymeric materials exposed to water at elevated temperatures.

\section{Experimental Work}

\subsection{Materials}

Unfilled polytetrafluoroethylene (PTFE) as a reference material and three of its commercially available composites procured from Fluorocarbon Company Limited, United Kingdom were used in this study. The details of the material characteristic are given in Table 1. Materials were selected due to their availability and their ability to further develop previous work on the tribological behaviour of PTFE-based materials. Tribo-testing of the polymeric materials was carried out against Inconel 625 discs due to their superior corrosion resistance in water-lubricated sliding contact [17]. 
Table 1. Polytetrafluoroethylene (PTFE)-based materials' characteristics.

\begin{tabular}{cccc}
\hline Specimen & Filler & $\begin{array}{c}\text { Filler Content } \\
\text { (wt \%) }\end{array}$ & Shape and Size of the Filler \\
\hline PTFE & Unfilled & - & - \\
Bronze PTFE (PB) & Bronze & 40 & Irregular shape particle; $2-28 \mu \mathrm{m}$ in size \\
Black glass fibre & Glass Fibre & 25 & Fibre; mean diameter of the cross-section, $17 \mu \mathrm{m}$ \\
PTFE (PGF) & Glass Fibre & 20 & Fibre; mean diameter of the cross-section, $17 \mu \mathrm{m} ;$ \\
$\mathrm{MoS}_{2}+$ Black glass fibre & $\mathrm{MoS}_{2}$ & 5 & Powder (crushed); $4-74 \mu \mathrm{m}$ in size \\
PTFE (PGFM) & &
\end{tabular}

\subsection{Test Specimens}

Square-shaped test specimens in sizes of $30 \mathrm{~mm} \times 30 \mathrm{~mm} \times 4.1 \mathrm{~mm}$ were machined from the fabricated composite for the purpose of conducting the hygrothermal ageing process. The polymer pins used for the tribo-test were cut from polymer blocks in cubic form with sizes of $4.1 \mathrm{~mm} \times 4.1 \mathrm{~mm} \times 4.1 \mathrm{~mm}$. The one-mm thick Inconel 625 discs were first manually grounded using \#240P SiC abrasion paper on Buehler MetaservTM 250 Twin Grinder-Polisher (Buehler, Lake Bluff, IL, USA) to a surface roughness of $R_{\mathrm{a}} \approx 0.08 \mu \mathrm{m}$, and were subsequently finished by abrasion against emery paper of $\# 120 \mathrm{P}_{2} \mathrm{O}_{3}$ to a surface roughness of $R_{\mathrm{a}} \approx 0.23 \mu \mathrm{m}$ in order to attain consistent surface roughness characteristics. This procedure was selected to maintain uniform topographical characteristics of the discs before the experiments.

Prior to testing, both the pin and the disc surfaces were cleaned for two and five minutes, respectively. The polymer pins were cleaned in an ultrasonic bath using ethanol in order to detach any possible contamination or dirt; then, they were dried using a stream of compressed air for two minutes. The disc surfaces were cleaned with a cloth soaked in acetone, and later utterly dried.

\subsection{Hygrothermal Ageing Calculations}

In other studies, the polymer was dried in an oven until its weight stabilised before the beginning of laboratory testing. This may present an inaccuracy, as the polymer would not be dried before the operation in real-life applications [3-11]. Therefore, in this study, ageing was carried out without drying the samples prior to immersion in water in order to make them comply with real applications. The absorbed water of polymeric material was measured using gravimetric analysis. The relative uptake weight of the aged samples was recorded in accordance with the exposure time. The gravimetric method involves removing the specimens from distilled water and measuring the weight at regular intervals with the digital balance of 0.1-mg accuracy.

The studied specimens were immersed vertically into a distilled water bath at different temperatures $\left(20-23^{\circ} \mathrm{C}\right.$ and $\left.80^{\circ} \mathrm{C}\right)$ for different time periods. No side of the specimen was covered in order to accelerate the diffusion process. The surfaces of samples were wiped with tissue paper for two minutes and weighed immediately. The uptake moisture of specimen at a given time, $t$, is defined by $M_{t}$ according to Equation (1):

$$
M_{t}=\frac{W_{t}-W_{0}}{W_{0}} \times 100(\%)
$$

where $W_{0}$ is the initial weight of the non-aged specimen, and $W_{t}$ is the weight of the wet specimen at time $t$. Different moisture absorption models (Fickian or non-Fickian) could be theoretically distinguished by the appearance of the sorption curve as follows in Equation (2) [18]:

$$
\frac{M_{t}}{M_{m}}=k \times t^{n},
$$

where $M_{\mathrm{m}}$ is the polymer's maximum water uptake at the equilibrium state, $M_{t}$ is the water uptake at time $t$, and $k$ and $n$ are the diffusion kinetic parameters. The diffusion parameter, $n$, describes the moisture absorption behaviour varying within three ranges of $n=0.5,0.5<n<1$, and $n=1$ (or $n>1$ ). The diffusion parameter $n=0.5$ and $n=1$ (or $n>1$ ) correspond to the Fickian diffusion mode and 
non-Fickian behaviour, respectively. However, diffusion behaviour is anomalous when $n$ varies between $0.5-1$. For a plain polymer block with a constant thickness of $h$, the one-dimensional Fick's law indicates that water absorption initially varies linearly with respect to time, and then gradually slows down until steady state is reached. For $M_{t} / M_{\mathrm{m}}$ values that are approximately lower than 0.6 , the initial part of the curve can be correlated with Equation (3) [18]:

$$
\frac{M_{t}}{M_{m}}=\frac{4}{h} \sqrt{\frac{D t}{\pi}}
$$

For the second half-sorption where $M_{t} / M_{\mathrm{m}}$ is higher than 0.6 , Shen and Springer [18] suggested a good approximation as follows (Equation (4)):

$$
\frac{M_{t}}{M_{m}}=1-\exp \left[-7.3\left(\frac{D t}{h^{2}}\right)^{0.75}\right]
$$

The crucial parameters of Fick's law, diffusion coefficient $D$, now can be determined from Equation (3), in the case where values $M_{t}$ are less than $60 \%$ of the equilibrium value $M_{\mathrm{m}}$ (Equation (5)):

$$
D=\frac{\pi}{\left(4 M_{m}\right)^{2}}\left(\frac{M_{t} h}{\sqrt{t}}\right)^{2}=\pi\left(\frac{k}{4 M_{m}}\right)^{2}
$$

where $h$ is the specimen thickness and $k$ is the slope of the linear part of the curve $M t=f(\sqrt{ } t / h)$.

\subsection{Experimental Setup and Material Characterisations}

\subsubsection{Tribo-Test}

Tribological tests were performed using a unidirectional pin-on-disc tribometer (TE67 Pin-on-Disc Tribometer, Phoenix Tribology, Kingsclere, UK) with the stationary polymeric cubic pin in contact with a rotating Inconel 625 disc. The experiments were carried out at room temperature $\left(21-23{ }^{\circ} \mathrm{C}\right)$, under an applied normal load of $84 \mathrm{~N}$ applied through dead weights resulting in an initial contact pressure of $5 \mathrm{MPa}$. All of the tests were performed under both dry and distilled water-lubricated conditions at a constant sliding velocity of $0.13 \mathrm{~m} / \mathrm{s}$, which is considered the lowest practical rotational speed achieved by the tribometer. Operating parameters were selected to minimise hydrodynamic effects and allow the contact to operate in a boundary/mixed lubrication regime along with the emulation of the maximum apparent contact pressure in the mating interface.

Regardless of the material used, each experiment was performed for an hour, which corresponds to a total sliding distance of $468 \mathrm{~m}$. For each material, at least three tests with good repeatability were performed. The subsequent plotted values are the means calculated from the data of these tests, and the error bars indicate the standard deviation of the mean. The friction force and the wear depth of polymer pin were continuously measured with a strain gauge force transducer and a displacement sensor, a linear variable differential transformer (LVDT), which was sequentially coupled to the pin holder. Both running-in and steady-state regions have been considered for the evaluation of wear rates.

\subsubsection{Fourier Transform Infrared Spectroscopy (FTIR)}

Bruker Vertex 80v FT-IR spectrometer (Bruker Optics, Germany) in ATR mode was used to analyse the functional groups at the surface of the PTFE polymer composite samples prior to and after hygrothermal ageing. The FTIR spectra were attained within the range of $400-4000 \mathrm{~cm}^{-1}$. 


\subsubsection{Differential Scanning Calorimetry (DSC)}

Differential scanning calorimetry (DSC) analysis was performed on a Mettler Toledo DSC821e instrument (Mettler-Toledo, Greifensee, Switzerland) and used to determine the crystallinity and melting temperature of polymers.

To eliminate the thermal history in the polymeric materials, the samples were heated from $30^{\circ} \mathrm{C}$ to $380{ }^{\circ} \mathrm{C}$ with a heating rate of $10^{\circ} \mathrm{C} / \mathrm{min}$ followed by an isothermal period of five minutes at $380^{\circ} \mathrm{C}$, and then were cooled to $30^{\circ} \mathrm{C}$ at a cooling rate of $10^{\circ} \mathrm{C} / \mathrm{min}$ to reduce impact of the thermal history of different specimens throughout the consolidation procedure.

The dynamic DSC measurements continued further by heating up the samples from $30{ }^{\circ} \mathrm{C}$ to $480{ }^{\circ} \mathrm{C}$. Data obtained from the last heating ramp was used for the evaluation of the normalised crystallinity of PTFE polymer composites as follows in Equation (6):

$$
\text { crystallinity }=\frac{\Delta H}{\Delta H_{100} \times\left(w t . \%_{\text {polymer }}\right)} \times 100 \%,
$$

where $\Delta H$ and $\Delta H_{100}$ are the measured enthalpy of the sample and the enthalpy of fusion for fully crystalline (100\%) PTFE considered being $82 \mathrm{~J} / \mathrm{g}$ [19]. For the crystallinity measurement, all of the experiments were conducted in an $\mathrm{N}_{2}$ purge chamber.

\subsubsection{Contact Angle and Surface Energy Measurements}

The hygrothermal ageing of polymer composites can potentially influence the wettability of the polymer composites surface, which in time might affect the tribological characteristic of the material. As the water diffuses into the contacting surface of the polymer, the polymer affinity for water is changed, and therefore influences the wetting properties and surface free energy. This may further alter the polymer's tribological response by the variation of adhesion. Hence, further investigations were performed to analyse the possible modification of the polymers' wettability after 132 days of hygrothermal ageing at two different temperatures; room temperature ageing values were used as a reference.

The experiments for measuring the wettability of the polymer samples were performed using a STFi contact angle measurement device with the 'static sessile drop' method (Attension Theta, Biolin Scientific products, Stockholm, Sweden) using distilled water and diiodomethane. A liquid drop of four $\mu \mathrm{l}$ was placed on the polymer surface using a microsyringe, and the drop was viewed using a high-speed digital camera $(1984 \times 1264$ [PX], 3009 frames per second (FPS). The drop image was digitised and the contact angle value was registered one second after deposition. In order to determine the wettability of the samples, a minimum of eight measurements was made for each polymeric material. Then, the surface free energies (SFE) of PTFE and its composites were evaluated using the contact angles formed by diiodomethane (non-polar) drops and water (polar) using the two-liquid OWRK/Fowkes method [20].

\subsubsection{SEM and EDS Analysis}

The counter-surfaces and the polymers' pin surfaces were analysed utilising Scanning Electron Microscopy (SEM) and Energy Dispersive X-Ray Spectroscopy (EDX) techniques. This was done before and after tribo-tests for both non-aged and hygrothermally-aged samples in both dry and water-lubricated sliding contact conditions. For this purpose, JEOL JSM IT-300 SEM (JEOL, Tokyo, Japan) coupled with an Oxford Instruments EDS detector was used for these analyses. 


\section{Results and Discussion}

\subsection{Water Absorption}

The absorbed water (wt \% relative to dry sample) and time to reach saturation level may be evaluated from two parameters: the highest moisture content $\left(M_{\mathrm{m}}\right)$ obtained and the one-dimensional Fickian diffusivity $(D)$ (calculated using Equation (5)), as illustrated in Table 2. The water uptake profile of hygrothermally aged polymer composites at two different temperatures (room temperature and $80{ }^{\circ} \mathrm{C}$ ) for an exposure period of 132 days is shown in Figure 1. It can be clearly seen that it follows classical Fickian behaviour, and shows that the kinetics parameters are affected by the temperature variation.

Table 2. Maximum moisture content and diffusivity of PTFE composites.

\begin{tabular}{|c|c|c|}
\hline \multicolumn{3}{|c|}{ Room Temperature } \\
\hline & $M_{\mathrm{m}}(\%)$ & $D\left(\mathrm{~mm}^{2} /\right.$ day $)$ \\
\hline Unfilled PTFE & $4.89 \times 10^{-3}$ & $2.06 \times 10^{-9}$ \\
\hline Glass fibre-filled PTFE (PGF) & $4.09 \times 10^{-1}$ & $2.80 \times 10^{-7}$ \\
\hline Bronze-filled PTFE (PB) & $3.82 \times 10^{-1}$ & $4.63 \times 10^{-8}$ \\
\hline Glass fibre and $\mathrm{MoS}_{2}$ (PGFM) & $1.79 \times 10^{-1}$ & $8.83 \times 10^{-8}$ \\
\hline \multicolumn{3}{|c|}{$80^{\circ} \mathrm{C}$} \\
\hline & $M_{\mathrm{m}}(\%)$ & $D\left(\mathrm{~mm}^{2} /\right.$ day $)$ \\
\hline Unfilled PTFE & $6.70 \times 10^{-3}$ & $5.47 \times 10^{-9}$ \\
\hline Glass fibre-filled PTFE (PGF) & $4.60 \times 10^{-1}$ & $1.44 \times 10^{-6}$ \\
\hline Bronze-filled PTFE (PB) & $4.33 \times 10^{-1}$ & $9.68 \times 10^{-8}$ \\
\hline Glass fibre and $\mathrm{MoS}_{2}$ (PGFM) & $1.06 \times 10^{0}$ & $1.22 \times 10^{-7}$ \\
\hline
\end{tabular}

Among all of the polymers, unfilled PTFE absorbed the least water in both cases (room temperature and $80{ }^{\circ} \mathrm{C}$ ). Glass fibre-filled PTFE showed the highest diffusivity at both temperatures. Furthermore, this polymer composite showed the highest obtained weight from water absorption at room temperature; however, at elevated temperature, the maximum water content was gained by $\mathrm{GF}+\mathrm{MoS}_{2}$-filled PTFE.

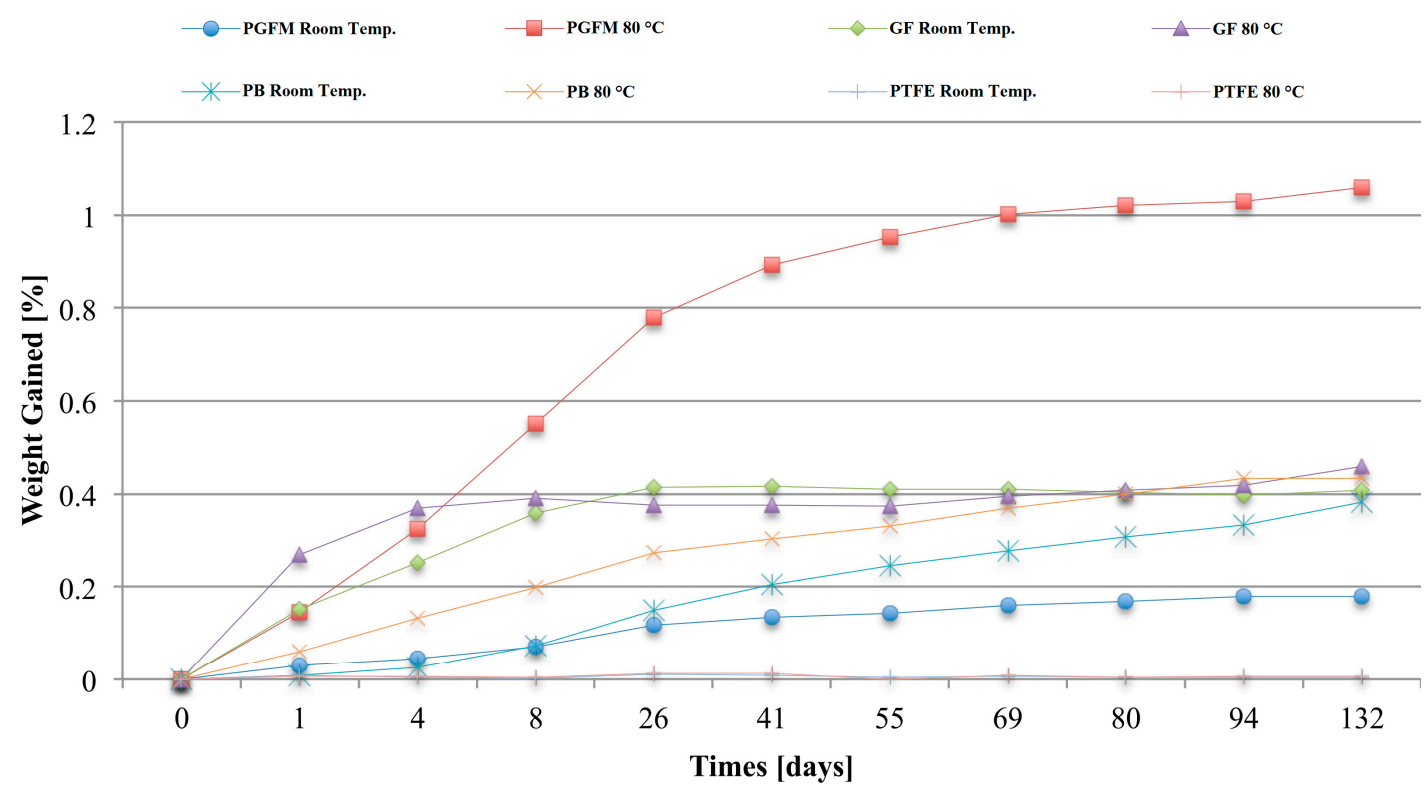

Figure 1. Water absorption of unfilled PTFE and its composites versus exposure time. 
The weight obtained from water absorption caused a colour change for bronze-filled PTFE at $80^{\circ} \mathrm{C}$, which was judged from visual inspection and presented in Figure 2 . The change in colour can be attributed to a mixture of copper oxide, (cuprite, $\mathrm{Cu}_{2} \mathrm{O}$ ) and tin oxide (cassiterite, $\mathrm{SnO}_{2}$ ), which formed in interaction with water at elevated temperature [21], and can be possibly continued by forming copper (II) hydroxide.
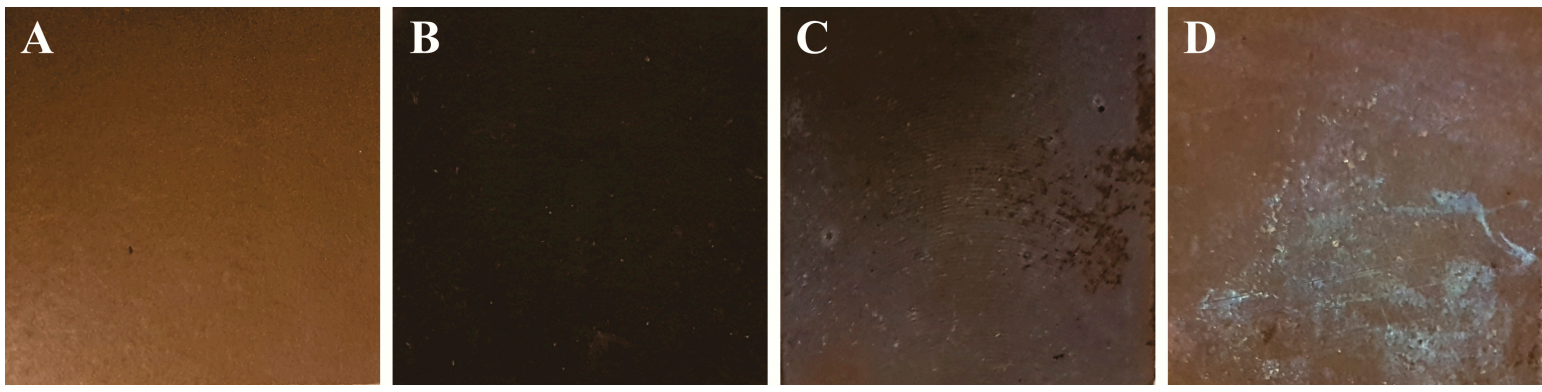

Figure 2. Colour changing for bronze-filled PTFE in $80^{\circ} \mathrm{C}$ for (A) zero-day (non-aged); (B) 26 days of conditioning; (C) 60 days of conditioning; (D) 80 days of conditioning.

Except for GF+MoS 2 -filled PTFE at $80{ }^{\circ} \mathrm{C}$ and bronze-filled PTFE at both ageing temperatures (room temperature and $80^{\circ} \mathrm{C}$ ), which are close to the equilibrium state within the timeframe considered, the water intake saturation level is achieved after 26 days of ageing for the rest of the polymers. It is believed that the mechanisms behind the obtained weight of bronze-filled PTFE are a combination of water accumulation at the interface and the bulk of the polymer, followed by a possible mass gain due to oxide growth and the possible self-healing of the bronze oxide layer [22].
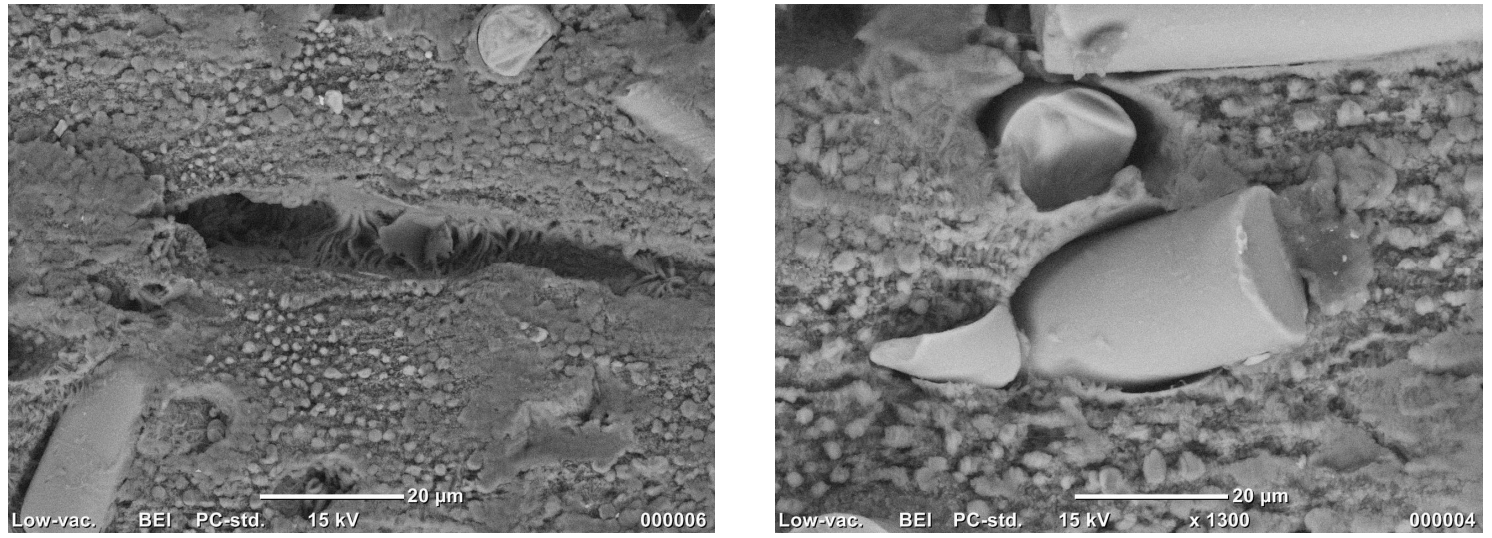

Figure 3. Manufacturing defect of PGF and/or debonding mechanism of PGF matrix/fibre after ageing (left and right).

Poor adhesion between the glass fibre and the matrix due to the non-polar nature of PTFE can exacerbate fibre/matrix debonding/discontinuity with hygrothermal ageing. Furthermore, manufacturing defects and volumetric expansion can contribute to the discontinuity, as shown in Figure 3. These lead to matrix-fibre debonding, creating extra voids that act as reservoirs for water absorption. Therefore, a weight increase in fibre-filled polymer composites (glass fibre (GF)-filled PTFE and $\mathrm{GF}+\mathrm{MoS}_{2}$-filled PTFE) is believed to be due to two dominating porosity-creating mechanisms: adhesive damage of fibre/matrix and/or the loss of interfacial integrity [4].

For GF+MoS 2 -filled PTFE, in addition to the above-mentioned mechanisms, the polarity of the sulphur compounds permits more water molecules to be conveniently absorbed into bulk containing molybdenum disulphide [23]. The saturation level at $80{ }^{\circ} \mathrm{C}$ is higher than that at room temperature for a sample containing $\mathrm{MoS}_{2}$ at the timeframe considered. This can be attributed to a strong effect of a thermally-induced stress on the filler/matrix interface. The creation of pores and the weakening of the 
interface during the hygrothermal ageing process may allow water absorption through capillary flow at higher temperatures.

\subsection{FTIR Measurements}

FTIR vibrational spectroscopy was used on both non-aged and hygrothermally-aged samples in this study. This was done to identify possible changes in the chemical bonds of polymeric materials during the ageing process. Figure 4 illustrates the progressive variation in the FTIR spectra of the samples before and after hygrothermal ageing. According to the literature, the most intense bands observed at $1145 \mathrm{~cm}^{-1}$ and $1203 \mathrm{~cm}^{-1}$ correspond to strong absorptions of the symmetric and asymmetric $\mathrm{CF}_{2}$ stretches, and the $\mathrm{CC}$ vibration band displayed itself in the form of curvature at around $1250 \mathrm{~cm}^{-1}$ [24]. The peaks observed at $640 \mathrm{~cm}^{-1}, 553 \mathrm{~cm}^{-1}$, and $507 \mathrm{~cm}^{-1}$ correspond to CF deformation, $\mathrm{CF}_{2}$ bending, and $\mathrm{CF}_{2}$ twisting, respectively.

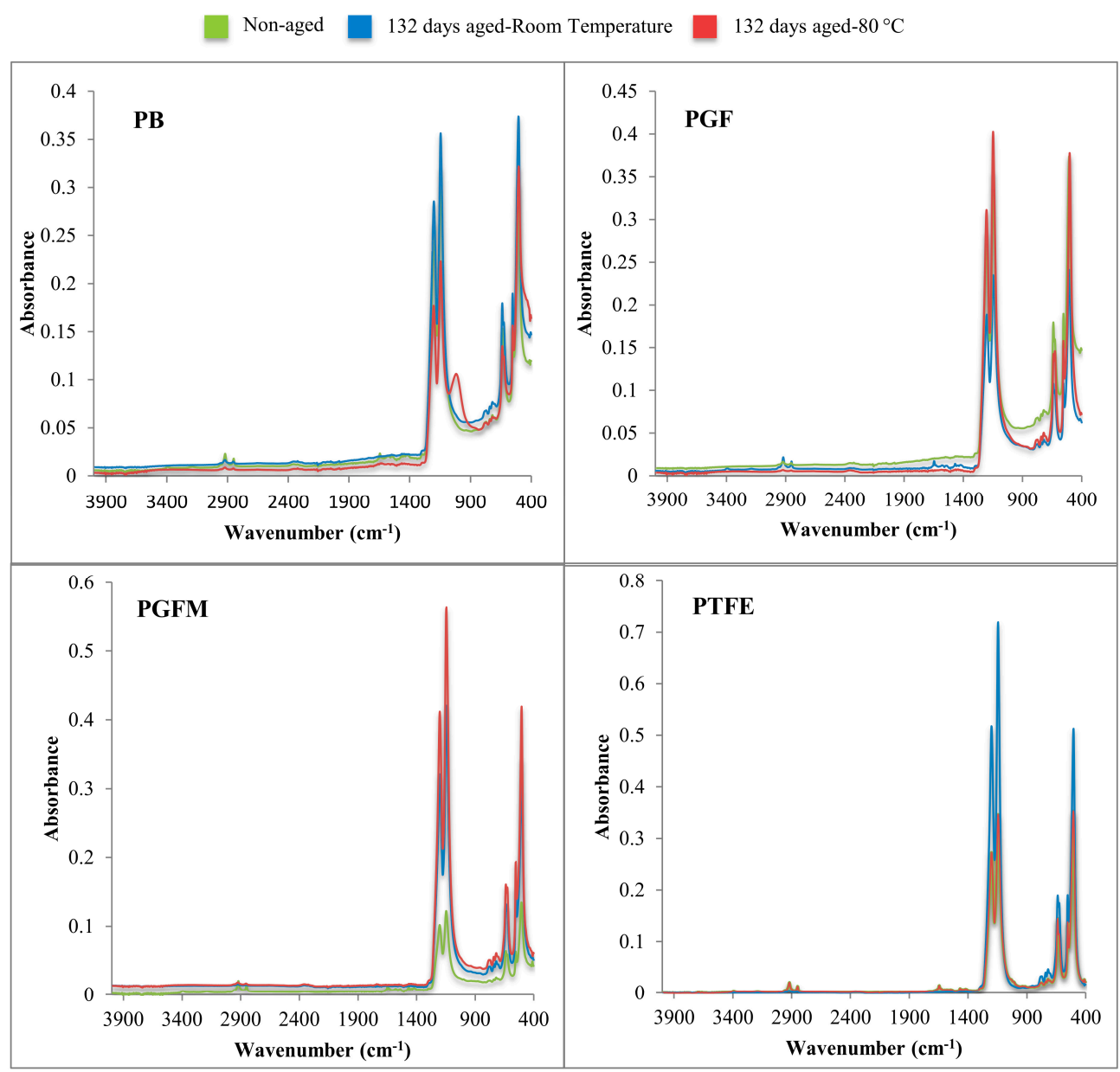

Figure 4. Fourier transform infrared (FTIR) spectra of PTFE and its composites.

The structure of the oxide layer formed on bronze-filled PTFE that was hygrothermally aged at $80{ }^{\circ} \mathrm{C}$ was confirmed by ATR-FTIR. The absorption band in 490-415 $\mathrm{cm}^{-1}$ manifested itself in the form of inflection that corresponded to the $\mathrm{Cu}-\mathrm{O}$ stretching mode [25]. The broad absorption band in $1040 \mathrm{~cm}^{-1}$ could be assigned to the possible stretching vibration of the O-Sn-O [26]. No other changes in the position of absorbance peaks were observed upon using different fillers within the matrix structure or different ageing conditions for rest of samples; meanwhile, the spectral differences between the different polymer composites fell in the range of a 0.25 absorbance unit or less. 


\subsection{Friction and Wear}

The obtained results from the tribological experimental setup were found to be reproducible, enabling comparison between the performances of non-aged and aged samples in different conditions. The results of the dynamic friction and specific wear rates of non-aged samples, 60-days aged samples, and 132-days aged samples, both in dry and water-lubricated sliding contact at two different temperatures, are shown in Figure 5.

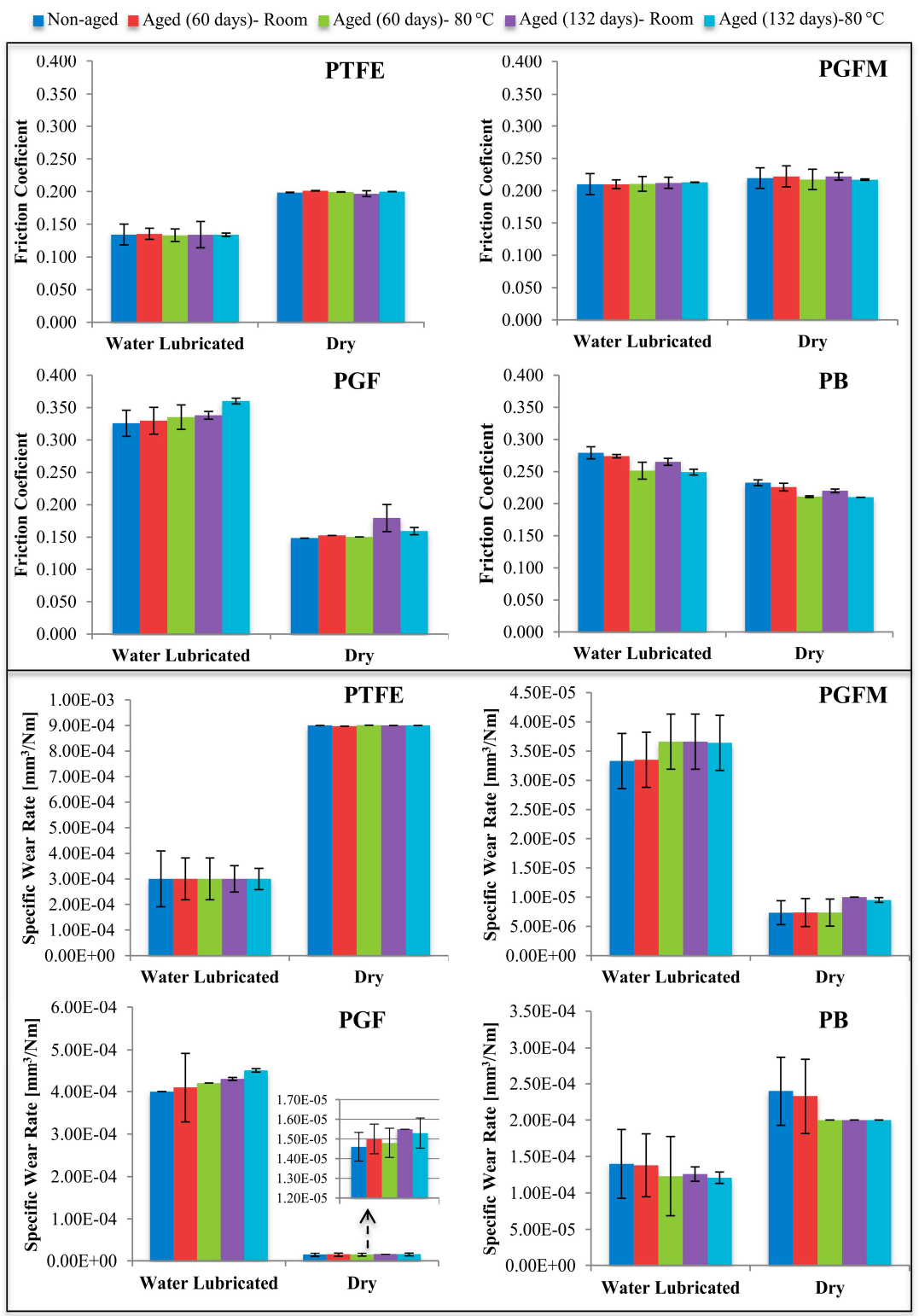

Figure 5. Average dynamic friction over the test time (up) and the specific wear rate of the polymer material (down). The error bars represent the standard deviation of the three repeated tests for each material.

The PTFE banded structure is easily destructible due to small slippage activation energy (Figure 6A) [27]. There are different hypotheses explaining the improvement of the tribological response, including wear by the addition of filler to PTFE. A preferential fillers load-supporting action, an improvement in the adhesion of transfer film $[27,28]$, and halting delamination wear by hindering subsurface crack propagation [28] are some of the most well-known theories. 
Depending on the nature, morphology, and volume concentration of the filler, there is a possibility that no sliding occurs between the PTFE and the counter-surface. Instead, sliding occurs between the filler and the counter-surface, the filler and the possibly formed tribofilm, the sample and the potentially formed tribofilm, or the feasible dynamic combination of the mentioned interactions.

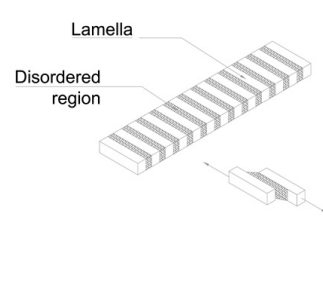

(A)

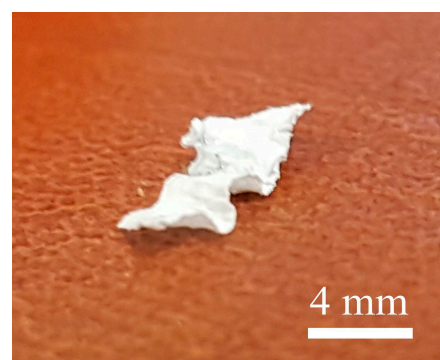

(B)

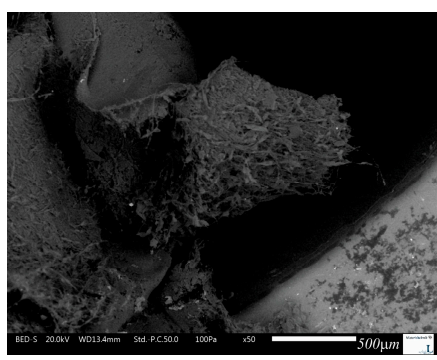

(C)

Figure 6. (A) Schematic illustration of PTFE banded structure and lamellae slippage over each other;

(B) and (C) flaky wear debris generated as a result of high wear rate of PTFE at different magnifications.

\subsubsection{Unfilled PTFE}

Unfilled PTFE is known for its low dynamic friction under certain conditions, relatively high melting point, low water absorbance, and chemical inertness because of the parent polymer. It is often used against metallic counter-surfaces to form friction pairs [29]. In this case, where there is a PTFE-metal pair, often the system has self-lubricating properties, which can be attributed to the formation of a thin protective layer of polymer on the counter surface; this is also known as a transfer film [27-29]. The tribological evolution of material in different conditions is shown in Figure 5. Furthermore, due to the large differences in the hardness of mating materials, no significant alternations in the initial counter-surface topography was observed. The results for dry conditions, water-lubricated conditions, and the effect of hygrothermal ageing on tribological behaviour will be discussed respectively in the following paragraphs.

\section{Dry Condition}

Based on the results shown in Figure 5, unfilled PTFE showed relatively low and stable dynamic friction along with poor wear resistance. The high specific wear rate of unfilled PTFE in dry conditions can be attributed to two main reasons:

- Higher heat generated as a consequence of the PTFE's low thermal conductivity and the absence of cooling lubricant [30]. Therefore, the matrix loses its integrity due to the reduction of bulk material strength and hardness [31] which is proceeded by less stable flake separation, as demonstrated in Figure 6B,C.

- Severe operating condition along with the nature of the counter-surface (Inconel 625) can result in the formation of no or discontinuous tribofilm [29,32]. It has been suggested that flaky wear debris could be generated from the delamination wear initiated because of operating in wear peak conditions at $\left(\sim 10^{-1} \mathrm{~m} / \mathrm{s}\right.$ and $\left.23^{\circ} \mathrm{C}\right)[29]$.

\section{Water-Lubricated Condition}

In water-lubricated sliding conditions, tribological behaviour improved compared to that in dry sliding contact (Figure 5). The reduction in dynamic friction and specific wear rate can be attributed to the following reasons:

- Better dissipation of generated heat in the friction interface

- Lubricous behaviour of water facilitating the sliding contact 


\section{Hygrothermal Ageing}

The hygrothermal ageing of the PTFE specimen does not seem to have a significant effect on the tribological behaviour of the material, which can be attributed to the negligible water intake of PTFE for the specified ageing time and the environmental conditions.

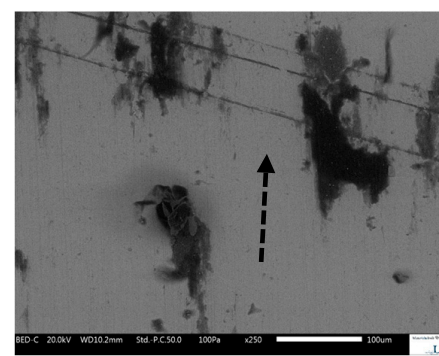

(A)

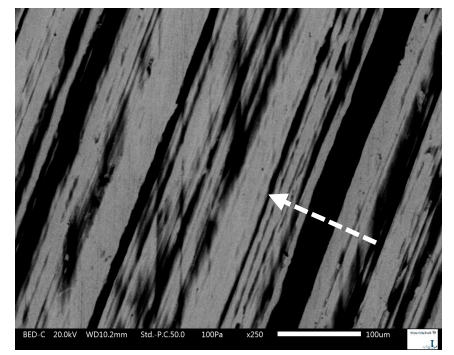

(B)

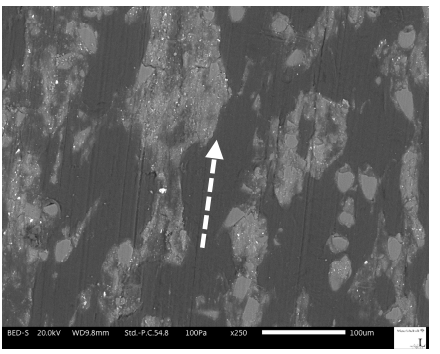

(C)

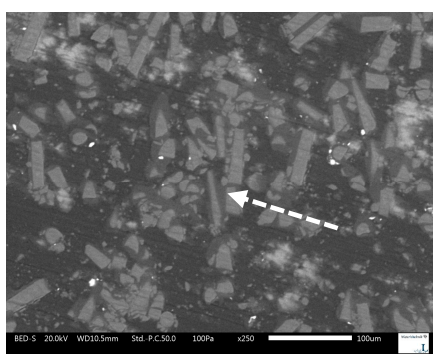

(D)

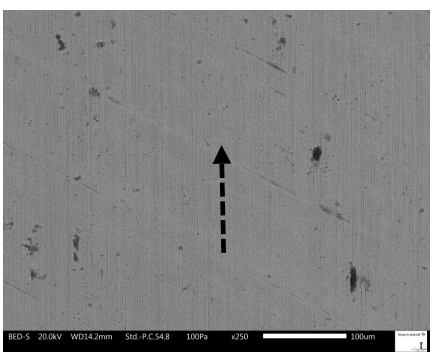

(E)

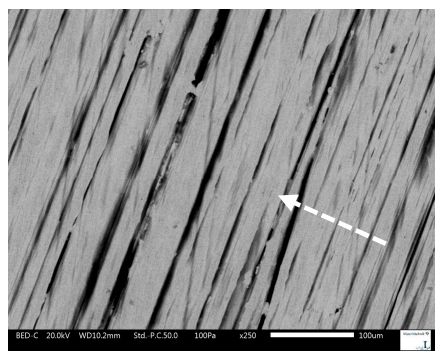

$(\mathrm{F})$

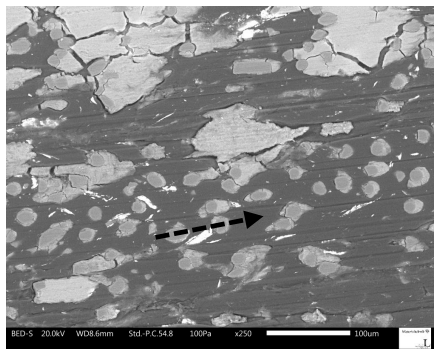

(G)

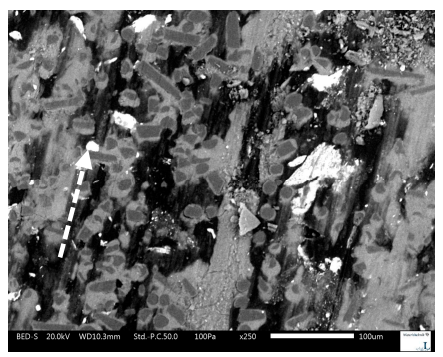

(H)

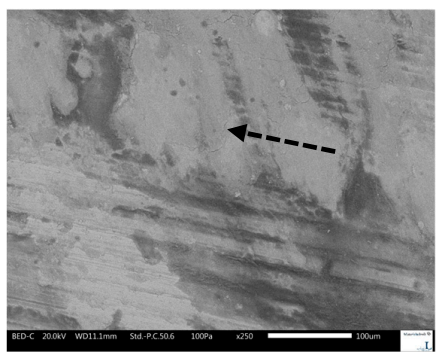

(I)

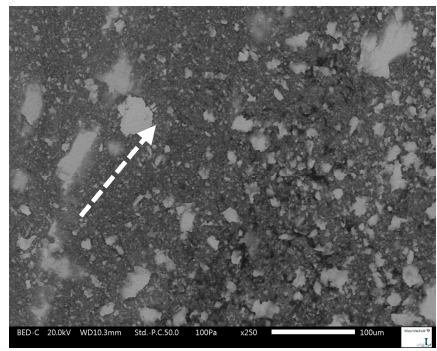

(J)

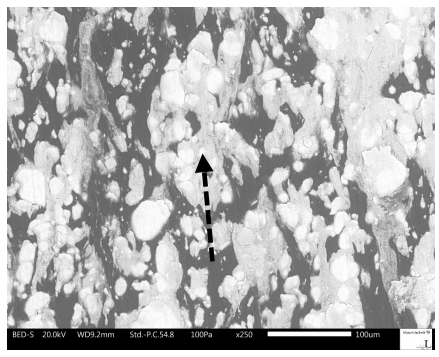

(K)

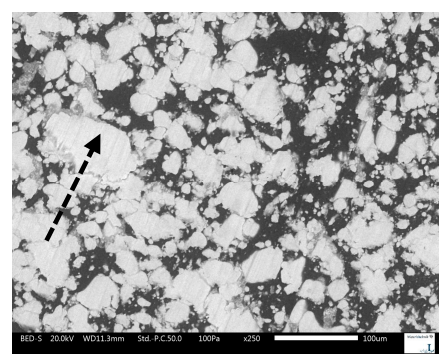

(L)

Figure 7. SEM image of: worn counter-surface sliding against (under water-lubricated contact), (A) PGF (E) PGFM (I) PB; Worn counter-surface sliding against (under dry condition), (B) PGF (F) PGFM (J) PB; Worn frictional surface (under water-lubricated sliding contact), (C) PGF (G) PGFM (K) PB; Worn frictional surface (under dry sliding contact), (D) PGF (H) PGFM (L) PB. Arrows indicate the sliding directions. 


\subsubsection{PTFE Filled with $25 \%$ Glass Fibre}

Figure 5 shows the tribological evaluation of PTFE filled with $25 \%$ glass fibre in different conditions. The SEM morphologies of wear tracks after tribo-tests and the worn surface of polymers under water-lubricated and dry sliding contact are shown in Figure 7A-D. The worn polymer surfaces in both sliding conditions show signs of scuffing, which can be ascribed to abrasive wear. In water-lubricated sliding contact, transformation in the initial topography of the counter-surface can be attributed to the cutting behaviour of the sharpened abrasive glass fibres during sliding contact alternating most of the initial lay orientation, as shown in Figure 7A. During the running-in period, an abrupt change in dynamic friction is expected for such alternations in surface roughness. In addition, Figure 7A shows large lumps produced by the accumulation of polymer composite on the counter-surface in water-lubricated sliding contact, which may result in a slightly fluctuated result. The results for dry conditions, water-lubricated conditions, and the effect of hygrothermal ageing on tribological behaviour will be discussed respectively in the following paragraphs.

\section{Dry Condition}

The incorporation of such a filler into a PTFE polymer matrix results in a significant improvement in the tribological behaviour in the dry condition (Figure 5). A closer examination of the wear track on the counter-surface in the dry condition, which is shown in Figure 7B, reveals the groove-filling mechanism of polymer transfer rather than the continuous formation of the transfer film. This can be ascribed to the mechanical interlocking of the transferred polymer in the valleys of the counter-body generated during the grinding process. A similar transfer mechanism was earlier reported under dry sliding contact [33]. The formation of such a discontinuous polymer transfer is believed to be a main reason for the reduction of dynamic friction compared to unfilled PTFE.

The SEM morphology of a worn GF-filled PTFE surface in dry condition shows a fibre-rich surface with relatively short fibres generated as a result of fibre breakage, which partially had been worn along the fibre length.

The fibre-rich surface shown in Figure 7D is assumed to be a result of the higher friction-induced heat generated in the absence of the lubricant. The higher local temperatures result in the reduction of hardness, which allows broken glass fibre particles to be re-embedded in the matrix. Furthermore, the reduction of mechanical properties allows the glass fibres to reorient themselves in the matrix, as can be seen in Figure 7D. Since the fibres are now parallel to the sliding direction, more wear occurs along the length of the fibres. It is hypothesised that this reorientation behaviour plays an important role in improving the material wear resistance and hindering crack propagation. A similar wear reduction mechanism was reported in the work of Tanaka et al. [27].

\section{Water-Lubricated Condition}

The dynamic friction of randomly oriented GF-filled PTFE composites is higher than that of unfilled PTFE in the presence of water (Figure 5). This can be due to the abrasive nature of GF-filled PTFE against the counter-body, since glass fibres are harder [34]. Moreover, the formation of a protective polymer transfer is hindered due to the presence of water at the mating interfaces.

The wear rate of randomly oriented GF-filled PTFE composites significantly increased compared to those in dry sliding contact. This can be attributed to the hindrance of the protective transfer film in the presence of water. Additionally, as a result of poor bonding between the filler and the matrix, the fillers were easily pulled out and detached from the matrix under an applied load of $84 \mathrm{~N}$, leaving cavities. Cavities within the structure of the polymer matrix led to stress concentrations in the matrix resulting in higher local stresses, possible microcracking, and consequently a high wear rate.

The change in the wear rate can also be related to the number of cavities. These cavities first serve as a water reservoir, further promoting the debonding process by modifying the polymer's surface structure [35]. They can later be filled by the amalgamation of wear debris from the counter-surface 
and crushed glass fibres, as confirmed by the elemental distribution analysis that is shown in Figure 8A. These reintroduced particles are crushed and cannot be compared to the fibrous particles in the dry conditions. Spreading of such an amalgamation on the interface of the polymer pin, which is shown as light grey spots in Figure 7C, results in limited PTFE-Inconel 625 contact, which further peels off the weak PTFE tribo-film formed on the counter-surface due to its abrasive nature, increasing the dynamic friction and polymer/metal wear.
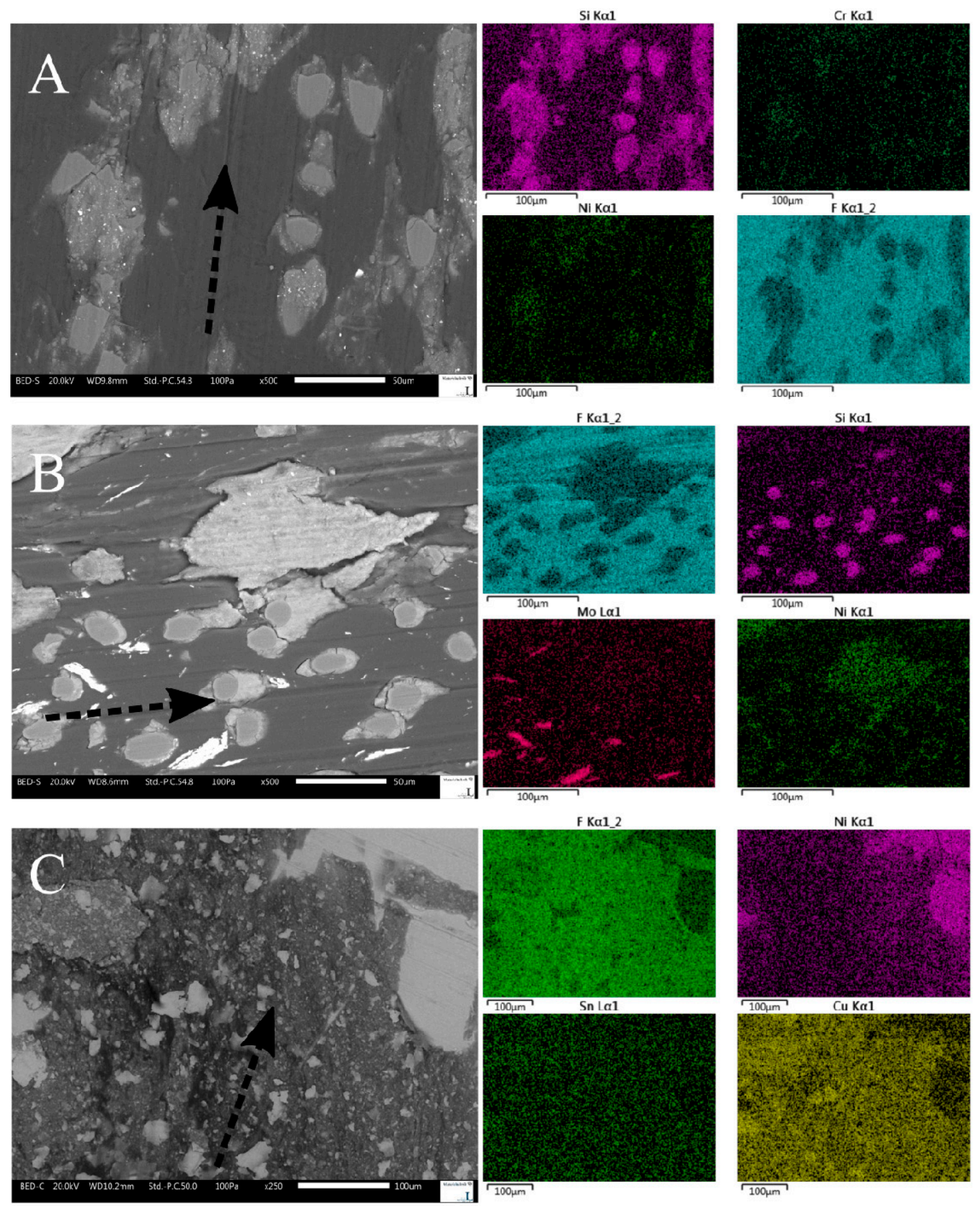

Figure 8. Energy dispersive X-Ray spectroscopy (EDX) analysis of: (A) Worn frictional surface of GF-filled PTFE under water-lubricated sliding contact; (B) Worn frictional surface of GF+MoS ${ }_{2}$-filled PTFE under water-lubricated sliding contact (C) Worn frictional surface of bronze-filled PTFE under dry sliding contact. Arrows indicate the sliding directions. 


\section{Hygrothermal Ageing}

Figure 5 reveals a slight increase in the dynamic friction and the specific wear of polymer in water-lubricated conditions during hygrothermal ageing. No significant change was noticed in the composite behaviour under dry conditions. This can be attributed to the reduction of moisture content as the temperature increases, which suggests the reversibility of the water uptake process. Therefore, the material is believed to experience some form of self-healing, and the performance is not significantly impacted by the selected ageing periods.

In water-lubricated conditions, the water further exacerbates the pull-out of fibres, as explained in Section 3.1. The tribological behaviour is impacted by the same mechanism as explained in the previous section. The coupling effect of the swelling stress and thermal stress increases with increasing temperatures during the ageing process. It is believed that at higher conditioning temperatures, hygrothermally-generated pores and weaker fibre/matrix interfaces may allow a capillary flow of moisture deeper inside the matrix. This is believed to be the reason why the tribological properties deteriorated for the sample conditioned at $80{ }^{\circ} \mathrm{C}$.

\subsubsection{PTFE Filled with $20 \%$ Glass Fibre and $5 \% \mathrm{MoS}_{2}$}

Figure 5 shows the average dynamic friction and the specific wear rate of GF+MoS ${ }_{2}$-filled PTFE in different conditions. The incorporation of $5 \%$ molybdenum disulphide, $\mathrm{MoS}_{2}$, to the PTFE filled with $20 \%$ glass fibre resulted in a similar dynamic friction as that of unfilled PTFE, while there is a significant reduction in wear. This can be due to the dominant structure of $\mathrm{MoS}_{2}$, which allows for its layers to be easily shearable due to weak Van der Waals forces between the lamellas [36].

The SEM morphologies of wear tracks after wear tests and the worn surface of polymers under water-lubricated sliding and dry sliding contact are shown in Figure 7E-H. Similar observations were made for GF+ $\mathrm{MoS}_{2}$-filled PTFE, which were comparable to those made in Section 3.3.2. Based on the elemental distribution analysis shown in Figure 8B, the light grey areas in Figure 7G were assumed to be a collection of counter-surface wear particles as they were found to be rich in nickel; that is one of the main elements of Inconel 625. The results for dry conditions, water-lubricated conditions, and the effect of hygrothermal ageing on tribological behaviour will be discussed respectively in the following paragraphs.

\section{Dry Condition}

In dry conditions, the tribological behaviour of GF+MoS 2 -filled PTFE is improved compared to unfilled PTFE (Figure 5). The intense polarisation of sulphur atoms producing a layered structure, strong adhesive forces between $\mathrm{MoS}_{2}$ and metallic surfaces, as well as basal planes resulting in easily shearable lamellae and enhanced transfer film formation are possible causes of this observation [23]. The SEM examination of the wear track in the dry sliding contact shown in Figure 7F reveals a similar transfer film mechanism as that described in "Dry Condition" segment of Section 3.3.2.

Water-Lubricated Condition

There is no noticeable change in the dynamic friction between dry and lubricated conditions (Figure 5). There is an almost fourfold increase in the specific wear rate of GF+MoS 2 -filled PTFE switching from the dry condition to water-lubricated sliding contact.

It can be clearly seen in Figure 7E,F that there is no sign of transfer film in the presence of water. This can be attributed to two possible scenarios: no formation of film, or the removal of the possible transfer film; in either case, the result is an increased wear rate and altered orientation of the initial lay. The film removal can be mainly attributed to the abrasive nature of the nickel-rich polymer surface. The expedition of the film removal process can possibly be attributed to a combination of the proposed hypotheses as follows: film softening, oxidation initiated by water, and escalated shear strength as a result of physical bonding at the boundary sites [37]. 
Hygrothermal Ageing

Excluding the running-in period, there is a negligible difference between the steady-state frictions of GF+MoS 2 -filled PTFE in both dry and water-lubricated conditions for the aged samples. However, the specific wear rate increased gradually throughout hygrothermal ageing.

The mechanism through which water affects the tribological behaviour is similar to that explained in "Hygrothermal Ageing" segment of Section 3.3.2. With increasing conditioning temperatures, possible capillary forces along with imperfections in the matrix facilitate water diffusion inside the matrix. This can lead to a weakening of the fibre/matrix interface and plucking, as explained previously.

\subsubsection{PTFE Filled with $40 \%$ Bronze}

Along with the PTFE's ability to provide the transfer film, the formation of a good transfer film on an Ni-based alloy (Inconel 625) surface is expected in sliding contact against copper alloy (bronze) due to the high affinity between both metals. Therefore, it is anticipated that the presence of copper compounds in PTFE provides considerable adherence to the counter-body and forms a relatively denser transfer film.

Figure 5 shows the tribological evaluation of PTFE filled with $40 \%$ bronze particles in different conditions. The SEM morphologies of worn surfaces, polymer pins, and the Inconel disc of the bronze-filled composites under water-lubricated and dry sliding contact against the Inconel 625 are given in Figure 7I-L. The worn surface of bronze-filled PTFE polymers under both sliding conditions shows scratches that are parallel to the sliding direction of motion due to abrasive wear.

It is shown in SEM micrographs of the worn interface of polymer samples in Figure 7K,L that the most of the polymer's contact region is occupied with bronze particles embedded in the PTFE matrix, which is shown as darker areas. These embedded particles in the PTFE matrix, at the frictional surfaces of composites, helps to support the load and reduce the wear, as bronze particles are more wear-resistant than unfilled PTFE. The worn Inconel surfaces under water-lubricated and dry sliding contact exhibit clear signs of adhesive wear, which is assigned to the deposition of the PTFE/bronze onto the Inconel Interface (Figure 7I,J). Such a transfer film is affirmed by the EDX analysis in Figure 8C. The results for dry conditions, water-lubricated conditions, and the effect of hygrothermal ageing on tribological behaviour will be discussed respectively in the following paragraphs.

\section{Dry Condition}

Lower dynamic friction in a dry condition, in comparison with the water-lubricated condition, could be assigned to the self-lubricity of the polymer composite at relatively high temperatures [38]. The self-lubricity of the composite is generally triggered by heat generated from friction; however, this leads to softening, plastic deformation, and decreased mechanical strength, and hence increased wear. Based on this, in dry condition considerations, the balance between self-lubricity and wear must be taken into account. A similar mechanism was earlier reported in the work of Jia et al. [38].

Water-lubricated Condition

When operating in water-lubricated conditions, the water hindered the friction-induced heat; hence, it prevented the composite from self-lubricating, which resulted in higher dynamic friction. However, in boundary conditions, if the applied normal load is high enough, the water could not compensate for the lack of self-lubricity of the polymer composite [38].

A smoother transfer film and declined adhesion under water-lubricated sliding contact is shown in Figure 7I. Despite the relatively thinner deposition of the composite matrix on the counter-surface in water-lubricated sliding contact, lower wear rates are observed. This could be due to the cooling effect of the water in contact, which would prevent the mechanical strength degradation of the composite due to elevated temperatures and allow the composite to resist wear. In addition, the balance between 
self-lubricity and wear does not need to be considered for water-lubricated applications of the same composite. A similar mechanism was earlier reported in the work of Jia et al. [38].

Hygrothermal Ageing

The dynamic friction and the specific wear rate were reduced after hygrothermal ageing. Hence, these findings further support the association between the formation of an oxide layer on the interface of the polymer pin and its tribological behaviour. Figure 5 further reveals the lubricity of the oxide layer in the same manner as a solid lubricant in comparison to unoxidised samples, reducing both the dynamic friction and the wear rate. The aforementioned oxide is believed to be initially part of the polymer's interface, and then is transferred to the counter-surface as a transfer film. Therefore, the formed oxide is believed to remain at the interface of the tribo-pair.

\subsection{Thermal Characterisation}

Evaluations of the materials' crystallinity and the melting temperature of PTFE polymer composites were carried out using DSC. The normalised results are shown in Table 3. The presence of filler could potentially enhance the polymer resistance to wear by modifying the PTFE's structure. When PTFE is undergoing the melting-crystallinity process, its molecules entangle with each other and form crystalline units. These units are composed of layers, which are separated from each other by poorly crystalline or amorphous regions.

Table 3. Evaluation of the PTFE specimen crystallinity and the melting temperature.

\begin{tabular}{|c|c|c|c|c|c|c|}
\hline \multirow{2}{*}{ Sample } & \multirow{2}{*}{$\begin{array}{c}\text { Melting } \\
\text { Temperature } \\
\left({ }^{\circ} \mathrm{C}\right)\end{array}$} & \multicolumn{5}{|c|}{ Degree of Crystallinity (\%) } \\
\hline & & $\begin{array}{l}\text { Non-Aged } \\
\text { Samples }\end{array}$ & $\begin{array}{l}\text { Two Months Aged, } \\
\text { Room Temperature }\end{array}$ & $\begin{array}{l}\text { Two Months } \\
\text { Aged, } 80^{\circ} \mathrm{C}\end{array}$ & $\begin{array}{l}132 \text { Days Aged, } \\
\text { Room Temperature }\end{array}$ & $\begin{array}{c}132 \text { Days } \\
\text { Aged, } 80^{\circ} \mathrm{C}\end{array}$ \\
\hline $\begin{array}{l}\text { Unfilled } \\
\text { PTFE }\end{array}$ & 329 & 30.46 & 30.42 & 30.43 & 30.47 & 30.41 \\
\hline PB & 330 & 27.48 & 25.98 & 23.46 & 23.53 & 23.22 \\
\hline PGF & 329 & 37.34 & 37.23 & 36.80 & 36.43 & 35.93 \\
\hline PGFM & 328 & 38.97 & 38.56 & 38.51 & 37.88 & 37.49 \\
\hline
\end{tabular}

It is believed that during hygrothermal ageing, water can be spread out within the amorphous regions of the semi-crystalline structure of the polymer, influencing the wettability, water absorption, and tribological properties of material over time [1]. There was no change in the transition melting point of the polymer composites before and after hygrothermal ageing using different fillers within the matrix structure. However, the degree of crystallinity was affected depending on the filler type, environmental conditioning, and duration of ageing.

With the exception of an unfilled PTFE sample, hygrothermal ageing has insignificantly deteriorated the thermal characteristics of the rest of the PTFE composites. The degree of crystallinity shows a slightly decreasing trend starting with the highest value in the non-aged sample followed by two months aged at room temperature, 60 days aged at $80^{\circ} \mathrm{C}, 132$ days aged at room temperature, and finishing with the lowest value in 132 days aged at $80^{\circ} \mathrm{C}$.

There is a clear trend in the relation between the degree of crystallinity and the specific wear rate values of samples tested in a dry condition where heat cannot be dissipated easily due to the absence of water. A comparison of data in Figure 5 and Table 3 shows that all of the polymer composites excluding bronze-filled PTFE have lower specific wear rates for a higher degree of crystallinity. It is believed that the specific wear rate of bronze-filled PTFE is controlled by the formation of an oxide layer.

Although the crystallinity of unfilled PTFE is high, the well-known conformation of alternated amorphous and crystalline parts allows for relative sliding facilitating wear. In addition, referring to the PTFE phase diagram in Conte et al. [30], at atmospheric pressure, the crystallisation of unfilled PTFE starts at low temperatures; therefore, the crystals are less resistant (higher wear) than those grown at higher temperatures. 
As can be seen in Table 3, the bronze-filled PTFE's relative degree of crystallinity is low. This can be attributed to the large $\mathrm{wt} \%$ content of bronze particles (40 wt \%) within the polymer matrix, which disturbs the formation of large crystals [30]. The presence of bronze is believed to play a role in the heterogeneous nucleation of PTFE during the melting-crystallinity process. According to this, the heterogeneous nucleation of the fillers is speculated to be responsible for both the lower degree of crystallinity and the formation of smaller crystalline units of PTFE molecules in PTFE composites [39].

The longer particles in the fibre-filled polymer are hypothesised to play a role in the internal stress distributions enhancing material properties against transverse loads. The relatively higher crystallinity of GF-filled PTFE and GF+MoS 2 -filled PTFE is believed to be because they allow the formation of large crystals and provide better heat dissipation by hindering the nucleation of crystals proportionate to the content of the filler [30]. However, further experimentation is required to confirm this hypothesis.

\subsection{Wettability and Surface Free Energy Analysis}

The wettability of polymeric material is known to be one of the parameters that affect the tribological behaviour of a polymer/metal material pair in water-lubricated sliding contact [1]. Figure 9 shows the average results of eight contact angle measurements at different PTFE composite surfaces with two liquids (distilled water and diiodomethane) before and after hygrothermal ageing. For non-aged samples, filler inclusion increased the measured contact angle, regardless of the liquid used, which was ensued by a reduction in the degree of wetting.

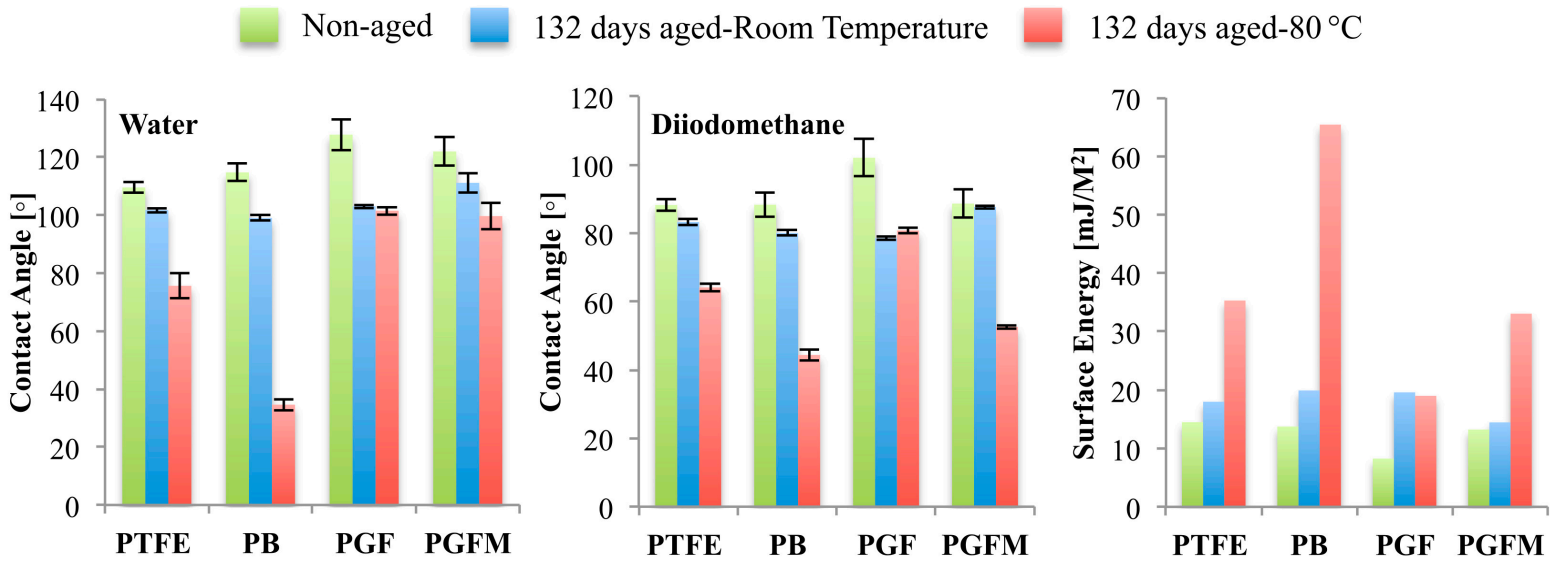

Figure 9. The average contact angle of polymers (water and diiodomethane) and total surface free energy (SFEs) of polymers. Error bars represent the standard deviation of the eight repeated tests for each material.

The measurements have experimentally confirmed the reduction in the degree of the contact angle using both liquids after 132 days of hygrothermal ageing. Almost all of the samples that were exposed to higher temperature showed lower contact angle values using both liquids in comparison to those that had been aged at room temperature. The results show a great reduction in the hydrophobicity of bronze-filled PTFE aged for 132 days at $80^{\circ} \mathrm{C}$, which can be attributed to the oxide layer formed on the specimen.

The surface free energies (SFEs) of the studied specimens are reported in Figure 9. Figure 9 shows that the SFE of almost all of the samples has increased by hygrothermal ageing. The data indicates that total surface free energy (SFE) is inversely proportional to the contact angle measurements. Except for the bronze-filled PTFE sample aged at $80{ }^{\circ} \mathrm{C}$, which had a polar component of around $37.6 \%$, the evaluated total surface energy of the rest of the samples mainly consisted of the dispersive component. The high polar component of surface energy for the bronze-filled PTFE sample aged at $80^{\circ} \mathrm{C}$ shows that the oxide layer that was formed can make a good polar interaction with the medium or counter-surface, altering the dynamic friction and wear by providing better lubricious adhesion. 
It has been suggested by Borutto et al. [40] that the lowest friction and wear can be obtained by mating two materials, polymer-metal, with different wetting properties. Moreover, the higher the hydrophobicity of the polymer, the higher probability of lower friction and wear [41]. Accordingly, using a pin-on-disc test configuration, coupling a hydrophobic polymer pin with a hydrophilic Inconel 625 disc could potentially improve the tribological response. Therefore, a reduction in the hydrophobicity of fibre-based PTFE composites, as a consequence of hygrothermal ageing, should result in the deterioration of the tribological response by lowering the hydrostatic lift ability, which perfectly complies with the results shown in Figure 5. However, further in-depth research on various material pairs with different lubricants as the medium needs to be conducted in order to conclude an association between material pairs/medium selection and their tribological behaviour. However, such a comprehensive research is beyond the scope of this work.

\section{Conclusions}

Upon conducting the experimental tests and the characterisation of worn and unworn interfaces of an unfilled PTFE polymer and three of its commercially available composites prior to and after hygrothermal ageing in two different conditions $\left(21-23^{\circ} \mathrm{C}\right.$ and $\left.80^{\circ} \mathrm{C}\right)$ for a period of 132 days, it can be concluded that the water uptake behaviour of almost all of the PTFE composites was found to follow the classical Fickian diffusion mode, where the water absorption kinetics variables, such as $M_{\mathrm{m}}$ and $D$, are influenced by the ageing temperature. The hygrothermal ageing influenced the microstructure integrity of the PTFE composites, resulting in numerous defects. An equilibrium plateau was reached for almost all of the samples within the timeframe considered. The obtained weight of fibre-based composites is due to existing voids, the adhesive damage of the fibre/matrix, and the loss of interfacial integrity, while for the bronze-filled composite, it is believed to be a combination of water accumulation at the interface and bulk followed by possible mass gained due to oxide growth and the feasible self-recovery of the bronze oxide layer. Exposure to moisture results in a decrease in the measured contact angle, crystallinity, and an increase in the surface free energy due to the degradation of the filler-matrix.

Tribological tests carried out at a constant sliding speed of $0.13 \mathrm{~m} / \mathrm{s}$ with a normal load of $84 \mathrm{~N}$ providing an apparent contact pressure of $5 \mathrm{MPa}$ have shown that fibre-based polymer composites that have a higher degree of crystallinity exhibited lower specific wear rates in dry conditions. The polymers' tribological behaviour is changed significantly in dry and water-lubricated sliding contact. Fibre-based PTFE composites showed an increasing trend for the dynamic friction and the specific wear rate by hygrothermal ageing, while this trend was the opposite for bronze-filled PTFE, attributing to the formation of an oxide layer on the interface.

Author Contributions: Data curation, M.R.H.; Formal analysis, M.R.H.; Investigation, M.R.H.; Methodology, A.G. and N.E.; Project administration, M.R.H; Supervision, N.E; Validation, M.R.H.; Visualization, M.R.H.; Writing-original draft, M.R.H; Writing-review \& editing, M.R.H, A.G and N.E.

Funding: This research received no external funding.

Acknowledgments: This research carried out at the Division of Machine Elements at the Luleå University of Technology as a part of the Joint Master Programme in Tribology of Surfaces and Interfaces, TRIBOS.

Conflicts of Interest: The authors declare no conflict of interest.

\section{References}

1. Golchin, A.; Simmons, G.F.; Glavatskih, S.; Prakash, B. Tribological behaviour of polymeric materials in water-lubricated contacts. Proc. Inst. Mech. Eng. Part J J. Eng. Tribol. 2013, 227, 811-825. [CrossRef]

2. Brostow, W.; Hagg Lobland, H.E. Materials: Introduction and Applications; John Wiley \& Sons: Hoboken, NJ, USA, 2017.

3. Ginzburg, B.M.; Tochil'nikov, D.G.; Bakhareva, V.E.; Anisimov, A.V.; Kireenko, O.F. Polymeric materials for water-lubricated plain bearings. Russ. J. Appl. Chem. 2006, 79, 695-706. [CrossRef] 
4. Ray, B.C. Temperature effect during humid ageing on interfaces of glass and carbon fibers reinforced epoxy composites. J. Colloid Interface Sci. 2006, 298, 111-117. [CrossRef] [PubMed]

5. Taktak, R.; Guermazi, N.; Derbeli, J.; Haddar, N. Effect of hygrothermal aging on the mechanical properties and ductile fracture of polyamide 6: Experimental and numerical approaches. Eng. Fract. Mech. 2015, 148, 122-133. [CrossRef]

6. Eftekhari, M.; Fatemi, A. Tensile behavior of thermoplastic composites including temperature, moisture, and hygrothermal effects. Polym. Test. 2016, 51, 151-164. [CrossRef]

7. Bárány, T.; Földes, E.; Czigány, T. Effect of thermal and hygrothermal aging on the plane stress fracture toughness of poly(ethylene terephthalate) sheets. Express Polym. Lett. 2007, 1, 180-187. [CrossRef]

8. Barraza, H.J.; Aktas, L.; Hamidi, Y.K.; Long, J.; O’Rear, E.A.; Altan, M.C. Moisture absorption and wet-adhesion properties of resin transfer molded (RTM) composites containing elastomer-coated glass fibers. J. Adhes. Sci. Technol. 2003, 17, 217-242. [CrossRef]

9. Mortazavian, S.; Fatemi, A.; Khosrovaneh, A. Effect of Water Absorption on Tensile and Fatigue Behaviors of Two Short Glass Fiber Reinforced Thermoplastics. SAE Int. J. Mater. Manuf. 2015, 8, 435-443. [CrossRef]

10. Illing, T.; Schoßig, M.; Bierögel, C.; Grellmann, W. Influence of hygrothermal aging on dimensional stability of thin injection-molded short glass fiber reinforced PA6 materials. J. Appl. Polym. Sci. 2015, 132. [CrossRef]

11. Valentin, D.; Paray, F.; Guetta, B. The hygrothermal behaviour of glass fibre reinforced Pa66 composites: A study of the effect of water absorption on their mechanical properties. J. Mater. Sci. 1987, 22, 46-56. [CrossRef]

12. Foulc, M.P.; Bergeret, A.; Ferry, L.; Ienny, P.; Crespy, A. Study of hygrothermal ageing of glass fibre reinforced PET composites. Polym. Degrad. Stab. 2005, 89, 461-470. [CrossRef]

13. Evans, D.C. Polymer-fluid interaction in relation to wear. In Proceedings of the Third Leeds-Lyon Symposium Tribology Wear Non-Metallic Materials; Mechanical Engineering Publications Limited for the Institute of Tribology: Leeds, London, 1978; pp. 47-55.

14. Autay, R.; Njeh, A.; Dammak, F. Effect of hygrothermal aging on mechanical and tribological behaviors of short glass-fiber-reinforced PA66. J. Thermoplast. Compos. Mater. 2018. [CrossRef]

15. Yousif, B.F.; Nirmal, U. Wear and frictional performance of polymeric composites aged in various solutions. Wear 2011, 272, 97-104. [CrossRef]

16. Palmeira Belotti, L. Tribological Performance of Hygrothermally Aged UHMWPE Hybrid Composites 2018. Available online: http:/ / www.diva-portal.org/ smash/record.jsf?pid=diva2\%3A1243332\&dswid=5262 (accessed on 22 November 2018).

17. Wang, J.; Chen, J.; Chen, B.; Yan, F.; Xue, Q. Wear behaviors and wear mechanisms of several alloys under simulated deep-sea environment covering seawater hydrostatic pressure. Tribol. Int. 2012, 56, 38-46. [CrossRef]

18. Shen, C.-H.; Springer, G.S. Moisture Absorption and Desorption of Composite Materials. J. Compos. Mater. 1976, 10, 2-20. [CrossRef]

19. Wingard, D. Use of DSC and DMA Techniques to Help Investigate a Material Anomaly for PTFE Used in Processing a Piston Cup for the Urine Processor Assembly (UPA) on International Space Station (ISS). In Proceedings of the 2010 North American Thermal Analysis Society (NATAS) Conference, Philadelphia, PA, USA, 16-18 August 2010.

20. Owens, D.K.; Wendt, R.C. Estimation of the surface free energy of polymers. J. Appl. Polym. Sci. 1969, 13, 1741-1747. [CrossRef]

21. Dortwegt, R.; Maughan, E.V. The chemistry of copper in water and related studies planned at the Advanced Photon Source. In Proceedings of the PACS2001, 2001 Part Accel Conf (Cat No01CH37268), Chicago, IL, USA, 18-22 June 2001; Volume 2, pp. 1456-1458. [CrossRef]

22. Miroshnikov, V.N.; Fedorchenko, I.M. Oxidation kinetics of bronze-graphite materials in boiling water and steam in the laboratory. Powder Metall. Met. Ceram. 1968, 7, 43-47. [CrossRef]

23. Holinski, R.; Gänsheimer, J. A study of the lubricating mechanism of molybdenum disulfide. Wear 1972, 19, 329-342. [CrossRef]

24. Ignat'eva, L.N.; Buznik, V.M. IR-Spectroscopic Examination of Polytetrafluoroethylene and Its Modified Forms. Russ. J. Gen. Chem. 2009, 52, 677-685. [CrossRef]

25. Dubal, D.P.; Dhawale, D.S.; Salunkhe, R.R.; Jamdade, V.S.; Lokhande, C.D. Fabrication of copper oxide multilayer nanosheets for supercapacitor application. J. Alloys Compd. 2010, 492, 26-30. [CrossRef] 
26. Pusawale, S.N.; Deshmukh, P.R.; Lokhande, C.D. Chemical synthesis and characterization of hydrous tin oxide $\left(\mathrm{SnO}_{2}: \mathrm{H}_{2} \mathrm{O}\right)$ thin films. Bull. Mater. Sci. Indian Acad. Sci. 2011, 34, 1179-1183. [CrossRef]

27. Tanaka, K.; Kawakami, S. Effect of various fillers on the friction and wear of polytetrafluoroethylene-based composites. Wear 1982, 79, 221-234. [CrossRef]

28. Lancaster, J.K. Polymer-based bearing materials. The role of fillers and fibre reinforcement. Tribology 1972, 5, 249-255. [CrossRef]

29. Blanchet, T.A.; Kennedy, F.E. Sliding wear mechanism of polytetrafluoroethylene (PTFE) and PTFE composites. Wear 1992, 153, 229-243. [CrossRef]

30. Conte, M.; Pinedo, B.; Igartua, A. Role of crystallinity on wear behavior of PTFE composites. Wear 2013, 307, 81-86. [CrossRef]

31. Li, D.; Celestin, A. TEFLON MECHANICAL PROPERTIES AT HIGH TEMPERATURE BY NANOINDENTATION. 2016. Available online: https://nanovea.com/App-Notes/temperature-nanoindentation.pdf (accessed on 22 November 2018).

32. Chen, Y.K.; Modi, O.P.; Mhay, A.S.; Chrysanthou, A.; O'Sullivan, J.M. The effect of different metallic counterface materials and different surface treatments on the wear and friction of polyamide 66 and its composite in rolling-sliding contact. Wear 2003, 255, 714-721. [CrossRef]

33. Sebastian, R.; Noll, A.; Zhang, G.; Burkhart, T.; Wetzel, B. Friction and wear of PPS/CNT nanocomposites with formation of electrically isolating transfer films. Tribol. Int. 2013, 64, 187-195. [CrossRef]

34. Ye, S.; Zeng, X. Tribological Properties of PTFE and PTFE Composites at Different Temperatures. Tribol. Trans. 2014, 57, 382-386. [CrossRef]

35. Lancaster, J.K. Lubrication of carbon fibre-reinforced polymers part I-Water and aqueous solutions. Wear 1972, 20, 315-333. [CrossRef]

36. Farr, J.P.G. Molybdenum disulphide in lubrication. A review. Wear 1975, 35, 1-22. [CrossRef]

37. Khare, H.S.; Burris, D.L. The effects of environmental water and oxygen on the temperature-dependent friction of sputtered molybdenum disulfide. Tribol. Lett. 2013, 52, 485-493. [CrossRef]

38. Jia, J.; Chen, J.; Wang, J.; Zhou, H. Friction and wear properties of bronze-graphite composite under water lubrication. Tribol. Int. 2004, 37, 423-429. [CrossRef]

39. Lai, S.Q.; Yue, L.; Li, T.S. Mechanism of filler action in reducing the wear of PTFE polymer by differential scanning calorimetry. J. Appl. Polym. Sci. 2007, 106, 3091-3097. [CrossRef]

40. Borruto, A.; Crivellone, G.; Marani, F. Influence of surface wettability on friction and wear tests. Wear 1998, 222,57-65. [CrossRef]

41. Vadivel, H.S.; Golchin, A.; Emami, N. Tribological behaviour of carbon filled hybrid UHMWPE composites in water. Tribol. Int. 2018, 124, 169-177. [CrossRef]

(C) 2018 by the authors. Licensee MDPI, Basel, Switzerland. This article is an open access article distributed under the terms and conditions of the Creative Commons Attribution (CC BY) license (http:/ / creativecommons.org/licenses/by/4.0/). 